\title{
Linguistic, Cognitive and Cultural Dimensions of the Narrative Written Production of Arabic and Spanish Speakers
}

\author{
Hosney M. El-daly \\ Associate Professor, Department of Linguistics, Faculty of Humanities and Social Sciences \\ United Arab Emirates University, P.O.Box: 17771, Al-Ain, U.A.E. \\ E-mail: hasan.mostafa@uaeu.ac.ae
}

Received: January 30, 2012

Accepted: March 7, $2012 \quad$ Published: April 1, 2012

doi:10.5539/ijel.v2n2p49

URL: http://dx.doi.org/10.5539/ijel.v2n2p49

\begin{abstract}
Ever since 1980s, much research has been done investigating the writing processes of $\mathrm{L}_{2}$ writers of different ages and abilities. Despite the abundance in such a research, there seems to be a dearth of studies on comparing the writing proficiency of both Arabic and Spanish speakers narrating in English. Motivated by such a huge research gap, this study was undertaken to answer the following questions: (1) what factors affect $\mathrm{L}_{2}$ learners accurate performance in writing, apart from their level of morphosyntactic competence? ; (2) from the cognitive perspective, do Arabic speakers differ from Spanish speakers during writing narrative texts?, and what is the nature of this difference (if it exists)?; and (3) from the cultural perspective, do Arabic speakers differ from Spanish speakers in writing narrative texts?, and what is the nature of this difference (if it exists)?.

The subjects were ten foreign graduate students at the University of Pittsburgh, USA. They belonged to two different linguistic and cultural backgrounds. The first was from the Arabic language group, and the second was from the Spanish linguistic group. The data were taken from (1) a questionnaire; (2) writing a narrative text, and (3) individual interviews. The data were analyzed both qualitatively and quantitatively. The linguistic analysis of the data focused on the numbers of errors in the light of how many words that each subject produced in his/her essay, and the reason for these errors. In addition, both the cognitive and cultural aspects of the subjects' written productions were examined and analyzed. Based on such analyses, recommendations were made.
\end{abstract}

Keywords: Narrative writing, Cognitive and cultural aspects of writing, Contrastive analysis

\section{Background and Statement of the Problem}

Recent attention to communicative competence, with its emphasis on sociolinguistic factors of language use, has led to the erroneous impression that communication is an oral phenomenon. In other words, communicating in English has always been associated with students' ability to speak appropriately. For too long, therefore, proficiency in English has meant only oral proficiency. Consequently it has been considered quite appropriate to wait a fairly long time before the initiation of writing composition instruction. A rationale for the delayed use of writing was grounded in principles of behavioral psychology and structural linguistics: written language was essentially a recording of speech, and a learner could code writing only through reference to the oral code which was previously and thoroughly mastered. As Terry (1989: 43) points out, 'of the four skills that are discussed and (supposedly) taught with equal emphasis in our foreign language classrooms, writing is perhaps the most poorly understood and the skill that is given, in fact, the most cursory attention'. Moreover, as early as 1970, some linguists and researchers tended to refer to communicative competence as a notion that is distinct from grammatical or linguistic competence. Omaggio (1986) maintains that for a period of years in the early to middle part of the decade, communicative competence became synonymous, in the minds of some researchers and practitioners, with a disregard for grammatical accuracy, and second language learners were considered communicatively competent if they got their meaning across to a listener, even if their grammatical accuracy was relatively low. Hence, the problem that teachers of English as a second language always encounter is that although some adult learners are successful at learning grammar rules which they have been taught and then using those rules productively and communicatively, most learners cannot utilize their intellectual understanding of the grammar of the language in communicative situations (El-dali, 2010; Hua, 2011; Locke, 2011).

Writing has now attracted the attention of researchers, practitioners and language teachers (See Boughey, 1997; 
Gaffield-Ville, 1998; Blanton, 1987; Mancie, 2000; Porte, 1995, Pearce, 1998). As Coombs (1986:115) suggests, "writing in a foreign language constitutes an important part of language proficiency. Like speaking, writing shows that the individual can use the language to communicate". In this regard, Buckingham (1979) also maintains that writing is no less communicative in intent than speech. Writing, like speech, is intended to reach a specific audience with specific, recognized characteristics, and has the intent of inducing, maintaining, or eliminating specific mental or physical behaviors in the reader. As Terry (1989: 51) maintains, 'we write to communicate both to ourselves and to others. We write because we need to communicate for social, business and professional reasons; we need to find out information; we need to give information' (see Centeno - Cortes, 2004; Braaksma et al. (2004); Knutson, 2006; Roca de Larios et al., 2006; Beare \& Bour dages, 2007; Van Weijen et al., 2008; Weijen et al., (2009). Pea \& Kurland (1987) maintain that the basic reasons for learning to write are (1) to write is to think and reflect, (2) writing can help communication with others, (3) writing may make one a better reader, and (4) writing can give writers a better sense of their own voice. They further claim that although not all people have the interest in writing as art, writing as communication is a necessary skill. (See Silva \& Leki, 2004; Canagarajah, 2002; Nation \& Macalister, 2011).

It must be emphasized that writing on one's mother tongue is a demanding task that calls upon several language abilities, as well as upon more general (meta) cognitive abilities. Writing in a second language is even more demanding, because several of these constituent, abilities may be less well-developed than in one's first language. For example, linguistic l=knowledge of the $\mathrm{L}_{2}$ may be limited, and the accessibility of this knowledge may be less rapid or automatic (see Schoonen et al., 2003). In addition, most existing writing models focus on the writing process (Flower \& Hayes, 1980, 1983; Kellogg, 1996) or on the development of writing proficiency (Bereiter \& Scardamalia, 1987) more than on the characteristics of the cognitive and linguistic resources needed for writing. However, process models do acknowledge that writers need to have certain resources available.

Ever since the $1980 \mathrm{~s}$, much research has been done investigating the writing processes of $\mathrm{L}_{2}$ writers of different ages and abilities. There are a series of controversial issues in second language $\left(\mathrm{L}_{2}\right)$ writing research (Casanave, 2004). As $\mathrm{Mu}$ and Carrington (2007) maintained, some researchers assert that $\mathrm{L}_{1}$ writing processes are different from $\mathrm{L}_{2}$ writing processes (Bitchener \& Basturkmen, 2006; Lee, 2005; Martinez, 2005). Other researchers emphasized the similarities of the two processes (Schoonen et al., 2003). Some other researchers argued that it is the cultural difference that results in $\mathrm{L}_{2}$ students' rhetorical organization problems (Kaplan, 1966; Scollon, 1999), while others negate this claim (Hirose, 2003). It is acknowledged that culture influences $\mathrm{L}_{2}$ writing, but the genre of the writing task completed by $\mathrm{L}_{2}$ writers, cognitive development and interlanguage development should also be taken into account.

Despite the abundance in research on $\mathrm{L}_{2}$ writing process, there seems to be a dearth of studies on the writing processes of Arabic and Spanish speakers narrating in English. In addition although the literature is replete with studies on the written production of second language learners, there has been (to my knowledge) no attempt to consider the writing proficiency of $\mathrm{L}_{2}$ learners from the various interdependent aspects that influence it. The majority of the studies that have been conducted on the writing of $\mathrm{L}_{2}$ learners have been concerned with a single aspect of the writing skill, either linguistic, cognitive or cultural. To my knowledge, no single study emphasized or investigated the three aspects combined. It is my contention that writing in a foreign/ second language involves, at least, three interrelated skills: linguistic, cognitive and cultural. In this regard, Taylor (1976) points out that regardless of language proficiency, a writer also needs to master the essentially non-linguistic intellectual and cognitive skills which underlie writing (Ferris \& Hedgcock, 1998; Lindemann, 2001). Moreover, there has been a great shift from examining the written product to focusing on the writing process. In this regard, Hairston (1982:84 maintains that "we cannot teach students to write by looking only at what they have written. We must also understand how that product came into being, and why it assumed the form that it did. We have to try to understand what goes on during the act of writing... if we want to affect its outcome. We have to do the hard thing, examine the intangible process, rather than the easy thing; evaluate the tangible product" (Lillis \& Curry, 2011; Tyler, 2011, Seglawitz, 2011).

\section{The Present Study}

\subsection{The Purpose}

This study was undertaken to answer the following questions: (1) what factors affect second language learners' accurate performance in writing, apart from their level of morphosynctactic competence?; (2) From the cognitive perspective, do Arabic speakers differ from Spanish speakers during writing narrative texts? And what is the nature of this difference (if it exists)?, and (3) From the cultural perspective, do Arabic speakers differ from Spanish speakers in writing narrative texts? And what is the nature of this difference (if it exists)? 


\subsection{Rationale}

Writing is viewed here as a complex process. In order to help $\mathrm{L}_{2}$ learners write effectively in a second language, researchers need to examine writing from, at least, three interrelated perspectives: (1) linguistic, (2) cognitive, and (3) cultural aspects. This view is compatible with Vahapassi's (1982) line of thinking. According to Vahapassi's (1982) analysis of the concept of writing, the important contextual factors in a writing situation are (1) cognitive demands related to the topic and content, (2) social and intersubjective demands of writing concerning the purpose and audience of writing, and (3) linguistic and rhetorical demands of writing concerning the mode of discourse. With this understanding in mind, writing is defined, here, as (1) a communicative act that differs from speech although both share some similarities. (2) A creative discovery process, (3) a problem solving activity, and (4) a complex process that is constrained by linguistic, cognitive, and cultural conditions. And, with this definition in mind, the present study is based on the following premises, drawn from Purves (1988) extensive research contrastive rhetoric: (1) morphosyntactic competence is only a prerequisite to writing in a foreign/second language. That is, the fact that a student can understand the structure of individual sentences in a language does not necessarily guarantee that he/she can produce coherent and communicative written texts in that language. In fact, several national studies have shown that students in the United States perform at a remarkably low level on writing tasks (Boyer, 1983). (2) A composition is a product arrived at through a process. Both are equally important for effective models of instruction. (3) Different composing conventions do exist in different cultures. Every culture has its own specific conventions that may distinguish it from other cultures. (4) Writing is a social phenomenon. It is an act for negotiating meaning with some identifiable set of human beings. And this requires far more than a minimal control of syntactic and lexical items in the target language. Finally, from a cognitive point of view, we might consider the fact that the demands on short term/working memory might exceed capacity because students must not only plan, compose, revise, and reflect but must also access vocabulary, grammar rules, etc (see Bitchener \& Basturkmen, 2006; Mamba, 2010).

\subsection{Hypotheses}

The general hypothesis of this study was that although the subjects in both groups have, supposedly, reached a high degree of competence in English as a target language, their overall performance in the tasks used in this study will display various degrees of competence in English. That is, by comparing the performance of the five subjects in each language group, and that of each group's members against each other, we expect to see various degrees of performance. Specifically, it was hypothesized that the overall competence of second language learners is not systematic all the way (Bialystok, 1982). This study hypothesized also that, although the subjects in both language groups may share certain structural and stylistic commonalities in writing tasks, culturally and linguistically specific features will be apparent in their writing products. Similarly, the subjects in both language groups may have distinctive sets of cognitive behaviors while writing the narrative story (See Sebba et al., 2011).

\subsection{Subjects}

The subjects of this study were ten foreign students at the University of Pittsburgh. They belonged to two different linguistic and cultural backgrounds. The first was from the Arabic language group and the Middle Eastern culture. The second was from the Spanish linguistic group and South American culture (See Table 1 in Appendix 3). The ten subjects were engaged in advanced graduate studies in various majors at the University of Pittsburgh. They can, therefore, be considered "advanced" language learners, and their overall competence in English is rather high.

\subsection{Instruments/Tasks/Analysis}

A questionnaire was administered to elicit information from each subject. The questionnaire (See Appendix I) consisted of two parts; each containing eight questions. The first part aimed at eliciting background information from each subject about his/her name, country, sex, age, linguistic repertoire and the extent of his/her exposure to the English language, either in his/her home country or in an English speaking environment. The second part of the questionnaire aimed at eliciting information about subjects' awareness of the nature of task they were asked to perform. Each subject in each language group was asked to write a narrative text on the topic stated in Appendix 2. After the subjects in both language groups wrote the narrative essay, they were interviewed individually. The interview with each subject focused on each student's written production in the narrative texts. Each subject was asked to describe how s/he approached the narrative text, how s/he started both essays, developed his/her thoughts and ended his/her essays. Each subject was asked to describe how s/he would write the same narrative essay in his/her native language; whether it would be the same or different, and finally how each subject perceived his/her native language and culture as possible factors in shaping his/her written production. This means that each subject was asked to retrospect and reflect on the cognitive aspects of his 
writing process of the text. Subjects' interviews were transcribed by the researcher and, then, reviewed by a native speaker of English with background in such tasks. The mechanism of conducting the interviews is based on Gass' (1983:277) claim that one of the ways to understand the mechanisms of $L_{2}$ learners' performance is to ask them (learners). Specifically, Gass suggests that for second language learners the ability to think and talk about language might involve abstract analyses of a number of different types. It might include, for example, (1) analyses of their own language, (2) a comparison between their native language and the target language, (3) a comparison between their native language and other languages previously learned, or even (4) a comparison between the target language and other languages previously learned. With this understanding in mind, the interview was considered as an opportunity for each subject to retrospect and talk about his performance and/or his/her knowledge. This interview was inductively-oriented.

Analyzing the data was based entirely on the individual's explanations, and aimed at accounting for the differences within and across the two language groups. Similarly, each subject's explanation of how he/she approached the narrative text, how he/she started both essays, developed his/her thoughts and ended his/her essays was reported. Each subject's explanation of how he/she perceived his/her native language and culture as factors in shaping his/her written-production was also reported. In addition, some statistical operations were carried out as will be seen later.

\section{Literature Review}

The literature review for this study is related to the way writing has been defined in the introduction. With this in mind, part one of the literature review deals with the similarities and differences between writing and speech. Part two treats the nature of writing. Three issues on the nature of writing will be reviewed: (1) writing as a creative discovery process, (2) writing as a complex cognitive process, and (3) writing as a problem-solving activity within cognitive psychology. Part three examines the relationship between writing and culture.

\subsection{Writing vs. Speech}

Both speaking and writing are communicative acts that require an awareness of social relationships and social expectations. For a speaker or writer to achieve a communicative purpose, a degree of understanding, common knowledge, and shared expectations must exist between speaker and listener, between writer and reader. This type of awareness is a part of pragmatic competence which requires both the speakers and writers to consider what have been called in sociolinguistic studies, "speech act, speech event, and speech situation". Further, the notion of monitoring, as used by Krashen (1987) can be applied to both speech and writing. In this regard, Bialystok (1981) suggests that monitoring is not restricted to speaking situations. Any language response may be monitored by reflection upon the formal aspects of the message and concern with its structure. The explicit, formal knowledge that the language learner has obtained may be used in any language encounter to improve the quality of the language (See Gass \& Mackey, 2011; Hinkel, 2011).

Despite these similarities between speaking and writing, composing written texts is a separate linguistic function, differing from oral speech in both structure and mode of functioning, even its minimal development requires a high level of abstraction (Vygotsky, 1962). Linguistically speaking, speech has the following characteristics: (1) a higher tolerance for repetition of a phrase or sentence than writing; (2) speech allows use of informal and abbreviated forms; (3) in speaking, precision in expression is not of ultimate concern since we can repeat, expand, and refine our speech according to the listener's reactions, and (4) speech can also be telegraphic. In writing, however, the primary means to convey intended messages are different. Writers must consider how they develop their sentences and the ways they organize them. Since there is no immediate audience feedback, written statements must be constructed more carefully, concisely, and coherently to ensure that our meaning is unambiguous. Cognitively speaking, the difference between writing and speaking lies in the nature of the acquisition processes of both skills. Speaking a language is learned through natural acquisition processes. Writing, on the other hand, is usually learned through formal instruction (Cooper \& Greenbaum, 1988). In contrast, they learn to write through formal instruction, normally in a school setting (Purves, 1988). Vahapassi (1988), also, points out that while it is true that the four basic skills of general verbal ability, reading, writing, speaking and listening are interrelated, writing is a much more school-based activity than are any of the other skills. Moreover, in contrast to speech, competence in writing usually develops much more slowly in first language acquisition. As Hughey et al. (1983: 5) point out, "one usually learns to write after having essentially completed the acquisition of the 'speaking' grammar" And, if this is the case with native speakers of a language, it will be easy for us to imagine how difficult writing in English would be for second language learners. Owens (1970) points out that the efforts of the foreign language learner are nothing but concealed translation because he does not have a functional command of English grammar, and he uses his native language in expressing his new 
experiences. On the other hand, Arapoff (1967) indicates that native speakers learn their language via a discover and transfer process in which they [native speakers] learn to recognize and to understand differences between sentences, and, consequently, they develop the ability to produce various sentences in the appropriate contexts. This ability is what Arab students lacked when they wrote their essays because they thought in Arabic when they wrote in English (El-daly, 1986).

Psychologically speaking, speech differs from writing by having what can be called situational context (Hirsch, 1977). That is, a speaker has a chance to see the audience, and receives immediate feedback. Consequently, in speaking both the speaker and the audience have some immediate control over the direction of the communication event. Here, the word "control" means that a speaker has the chance to direct the speech situation in the way he and his audience like, by using hand gestures, tone, speed, and loudness. Conversely, writing is largely a solitary act; it is communication formed in isolation, and the audience is rarely if ever present. Writing also allows for retrospective thinking. That is, having committed ideas to paper, writers may look back at their written output to check its appropriateness.

\subsection{Writing is a Creative Discovery Process}

Emig's (1971) classic study represented one of the first attempts to investigate what writers do when they compose. According to this study, students, while composing, seemed to exhibit a variety of behaviors, all of which indicated the non-linear nature of writing. Furthermore, one of the most important findings of Emig's study was that writing involved a continuing attempt to discover what it is one wanted to say. Writing, then, is a creative discovery procedure characterized by the dynamic interplay of content and language: the use of language to explore beyond the known content. In this regard, Perl (1979: 331) has pointed out that "Composing always involves some measure of both construction and discovery.... Rereading or backward movements become a way of assessing whether or not the words on the page adequately capture the original sense intended. Constructing simultaneously affords discovery. Writers know more fully what they mean only after having written it. In this way the explicit written form serves as a window on the implicit sense with which one began". Murray (1978: 30) also points out that "writing is exploration discovery of meaning, discovery of form - and the writer works back and forth, concentrating on one of the basic skills at a time so that he can discover what he has to say and how to say it more efficiently". Hughey et al.'s (1983) model of writing as a creative process appears to reflect a consistent pattern of what writers perform throughout the composing process. (See Matsuda, 2003; Ramanathan, 2003; Richelt, 2001; Schoonen \& Geldren, 2003; Robinson \& Ellis, N., 2011).

\subsection{Writing is a Cognitive Act}

Like researchers in other disciplines who also study mental processes, writing specialists found a way to define with clarity the invisible mental acts that comprise producing written language. By asking native speakers of English to think aloud as they wrote, saying whatever thoughts came to them in the midst of composing, researchers learned that writing consists of several main processes. They also learned that these processes do not occur in a particular order; rather, they take place recursively, with the writer stopping to plan in the midst of transcribing a paragraph or beginning to revise before s/he even has a word on the page(Chenoweth \& Hayes, 2001; Cumming, 2001). Recent studies of different cognitive activities involved in writing seek to identify its basic component processes and how they are managed during the activities of writing. In fact, cognitive studies of writing begin with the observation that writing is a complex cognitive task in which many cognitive demands impinge on the writer at the same time. Collins and Gentner (1980:52) viewed writing as "a process of generating and editing text with a variety of constraints such as structure, content, and goals". As Rubin (1983) points out, the most obvious conventions are those of spelling, word meaning, and grammar. However, these are not the only constraints. For example, Pea and Kurland (1987: 288) suggest that "one must....think about the objectives of the written piece, the anticipated audience, whether the topics and comments are known or new to the reader, the structure of arguments, and the genre of the composition as a whole (e.g. legal brief, essay, sonnet, mystery, business letter)". They further point out that taken separately, each of these constraints may be manageable, but taken together they can constitute a serious impediment to human memory and cognitive processing (See Numan, 2011).

Bereiter and Scardamalia (1987) propose that there are two basically different models of composing that people may follow; the first is the knowledge-telling model, and the second is the knowledge-transforming model. According to Bereiter and Scardamalia, the knowledge-telling model presents writing as a fairly natural task. The task has its difficulties, but, according to the model, they are handled in ways that make maximum use of already existing cognitive structures and that minimize the extent of novel problems that must be solved. Bereiter \& Scardamalia (1987: 9) claim that "Knowledge telling provides a natural and efficient solution to the problems 
immature writers face in generating text content without external support... The solution is available because it makes use of readily available knowledge,...and it relies on already existing discourse-production skills in making use of external cues and cues generated from language production itself"'. This model allows for large differences in outcome depending on the writer's knowledge of the topic of discourse and on the writer's sophistication in the literary genre. Bereiter \& Scardamalia (1987:10) suggest, however, that it is necessary to have another model in addition to knowledge telling. This model is called "the knowledge transforming model". Bereiter \& Scardamalia (1987:12) argue that "the distinctive capabilities of the knowledge-transforming model lie in formulating and solving problems and doing so in ways that allow a two-way interaction between continuously developing knowledge and continuously developing text" (see Grabe, 2001; Lee, 2005; Sasaki, 2000).

Flower and Hayes (1980), provide the third model of the composing process. It is an explicit account of the mental operations used by mature writers. The purpose of this model is thinking about writing by describing the cognitive processes of writers and how they work together to create a written text. According to this model, three major elements of the task of writing are distinguished: (1) the task environment; (2) writer's long-term memory; and (3) writing processes. First, within the task environment three main elements are included: (1) There is a rhetorical problem to solve. Writing is the task of solving that problem, given some definition of topic and audience. (2) There is an evolving text which opens or closes off options for continuous writing. A topic sentence, for example, serves to limit and refine a paragraph's possibilities. (3) There are resources and tools for writing, such as teachers, books, index cards, and other reference and writing materials. Second, within the writer's long-term memory (LTM), there is knowledge about topic, audience, writing plans, and types of writing problems. Unlike the active processing of short-term memory, LTM has a more stable organization. The two major problems for the writer are to access the knowledge from LTM that will be useful for the writing under way, and to organize that knowledge to meet the needs of the rhetorical problem. Third, within "writing processes" four major mental processes are identified: (1) planning; (2) translating; (3) reviewing, and (4) monitoring. Using Flower and Hayes' model as a tool for observing the progress of writing activities has led to several important empirical findings. (1) Writing processes are hierarchically organized. This observation counters 'stage models' of writing that view text composing as a linear process of distinct stages such as Pre-write, Write, and Rewrite (Rohman, 1965). (2) The guidance of writing processes emerges from goal directedness, which guides a writer to invoke specific mental processes during the act of composing, thus giving writing its purposefulness. (3) The goals of writing are epistemically reactive, that is, they are continually regenerated through what is learned during the writing process. In this regard, Pea and Kurland (1987:292) also point out that "while many goals for writing may be automatically accessed from memory, the creative setting of subgoals and the subsequent discovery or redefinition of writing goals during the composing process is a basic fact about mature writing" (See Zimmerman, 2000; Wang, 2005).

\subsection{Writing is a Problem Solving Activity}

Simon (1970) described writing as a "problem solving activity". In his book, "The Sciences of the Artificial", Simon classified writing, among other disciplines, as an "artificial system". Such a system is not a set of relationships that exists in nature for humans to discover, but rather one that is devised by humans themselves to connect two differing environments. Writing connects the environments of individual inner thought processes and the outer world. According to Simon, people create artificial systems to solve problems; hence writing by its very nature is a problem-solving activity. It must be borne in mind, however, that there is a major difference between recent work on writing development and earlier cognitive science accounts of problem solving for other content areas. This major difference lies in the broader sense given to the term "problem solving". Whereas earlier studies emphasized the solving of problems with well-defined goals, it is now recognized that tasks, goals, and subgoals can emerge and are altered during work on a problem (Khaldieh, 2000; Wang \& Wen, 2002; Woodall, 2002; Hirose, 2003).

\subsection{Culture and Writing Discourse}

There has been another revolution in our thinking about writing in recent years, and it has come from learning to view writing as a process that is embedded in a context. In this regard, Hull (1989:109) maintains that "to say that writing is embedded in a context is to acknowledge that what counts as writing, or as any skill or any knowledge, is socially constructed. It depends for its meaning and its practice upon social institutions and conditions. According to this view, writing does not stand apart from people and communities ..... And this new understanding carries with it different notions of how writing is acquired and by whom". It has been recognized that writers from different cultures have learned rhetorical patterns that may differ from those used in academic 
settings in the United States and that are reinforced by their educational experience in their specific cultures (Purves, 1988). Kaplan (1966) attempted to analyze how one's native thinking and discourse -structures manifest themselves in the writing of ESL students. Influenced by the Sapir-Whorf hypothesis, Kaplan argued that his subjects revealed evidence of culturally-influenced styles of thought development that emerge in their writing in ways that can be structurally and stylistically described. In fact, the notions that cultures express concepts and develop perceptions of the word and of relationships of various kinds in different ways are not new. What is new, as Heath (1983) suggests, is the current attempt to integrate the study of languages and their uses in society in such a way as to reflect differences in cultural habits and differences in styles of expression in various contexts, including that of written text (See Gregorious, 2011; Walker, 2011).

Vahapassi (1988) proposes that different cultures differ in terms of the functions of writing emphasized in school, typical writing assignments, appropriate topics to write about and appropriate form of task instruction. That is, the approach to writing instruction adopted in different cultures and school systems is related to the general goals of education, the conception of language functions, and the process of writing. Fundamentally, educational views, including the goals of education, are shaped by the nature of the society in which the school system is embedded, including the goals of writing instruction (Hinkel, 2004; Connor, 2002). Scribner \& Cole (1981) and Heath (1983) examined the relation of culture to discourse and particularly to written discourse. Both studies pointed to the fact that written texts, and the ways in which they are used and perceived, vary according to the cultural group to which an individual belongs. In addition, both studies pointed to two aspects of that variation: the content or what is written, and the rhetorical forms used to encode that content, both of which constitute the surface manifestations of cultural differences. Scribner and Cole, and Heath suggest also that behind these surface manifestations of culture difference lie three other aspects of discourse, and particularly written language. The first of these aspects is the relative stress given to the functions of discourse. The second is the cognitive demand of the discourse, that is, the degree to which the writer must "invent" either the content of the 'written text or the form of the text. The third is the pragmatics of discourse". In this regard, Purves (1988) maintains that written language and the activities involved in composing or reading and responding are highly conventional (Mu \& Carrington, 2007; Casanove, 2004).

To sum up, both the content and the language to express this content are culturally determined. To be effective, writers have to learn what is expected of them within their own culture. Consequently, differences in cultural expectations are an obstacle for those who are learning to write in a foreign language. Under the influence of the norms within their own culture; they may deviate from the norms of the foreign culture in what kind of material are to be included in a particular variety of written discourse, what style is appropriate, and how the discourse is to be organized (Cooper \& Greenbaum, 1988). Purves (1988:19) points out that "...the differences among rhetorical patterns do not represent differences in cognitive ability, but differences in cognitive style. When students taught to write in one culture, enter another and do not write as do the members of the second culture, they should not be thought stupid or lacking in "higher mental processes". Recalling Rumelhart's (1975) notion of Schema theory, it appears that in order for $\mathrm{L}_{2}$ learners to write effectively in a second language, they must develop the schemata related to the written rhetorical styles of the target language. Thus, the $\mathrm{L}_{2}$ writer has to become familiar not only with the linguistic forms of the language but also with the written discourse patterns and conventions of that language. According to Purves (1988), the following conditions need to be met in cross-cultural studies: (1) the basic premise of contrastive rhetoric is that we must deal with at least two groups of writers; (2) the settings in which the writing occurs should be as similar as possible; (3) the writing task should be consistently set in its function and cognitive demand as-well as in the specific subject matter; (4) the language in which the writers are writing must be defined; (5) the occupation of the writers should be similar or, if not, should be defined and accounted for as variable, and (6) the education of the writers should be similarly defined and described. Furthermore, Soter (1988) points out that one of the chief problems in setting common tasks for culturally and linguistically diverse groups is in finding common experience in the mode of writing selected, as well as knowledge of the subject matter to be written about. In the present study, the genre of writing usedwas narration. The rationale for choosing narrative tasks is as follows: (1) it is more likely that all of the students in the present study would have had experience with narration, whether in oral or written form; (2) narrative compositions are the first type of composition that students learn in their native language (Indrasuta,1988); (3) narration is a socially evolved genre (Scribner, 1977); (4) such genres as narration may vary from culture to culture and from speech community to speech community (Hymes, 1974), and (5) narration is also a familiar form and based on a simple type of organization (Riessman, 1993). 


\section{Results / Discussion}

\subsection{Linguistic Analysis}

In order to get a real understanding of the subjects' performance, we need to consider the number of errors in the light of how many words that each subject produced in each essay. Table (2) presents the performance of both Arabic and Spanish subjects in the narrative essay. The reader is reminded that the Arabic subject (1) and the Spanish subject (4) are excluded from the study because they did not make any grammar errors in their essays (See Appendix).

Table (2) shows some characteristics of the students' performance in writing. First, the total number of words produced in the narrative essays ranges from 300 (Arabic subject 4) to 773 (Spanish subject 1), and the number of errors ranges from 3 (Arabic subject 3) to 22 (Spanish subject 5). As seen in table (2), in and across the two language groups, students' written productions were not quantitatively correlated to the number of their errors. That is, it is not necessarily the case that the more an individual writes, the more errors that he/she will make. Examining the data reported in Table (2) shows that some subjects were able to produce many words without making any grammar errors, such as Arabic subject (1) and Spanish subject (4). Other subjects were able to produce a large number of words with the least number of errors, such as Arabic subject (3). The ratio of the number of the words that Arabic subject (3) produced to the number of his errors in the narrative essay is 158:1. That is, he made one error in each 158 words, which is the highest ratio among the eight subjects. Other subjects produced the least number of words, but made the highest number of errors such as Spanish subject (5). The point, here, is that judging students' performance only on the basis of their words and errors, although important, might lead to a misleading conclusion. We might conclude, for example, that the Arabic subject (5), who produced more words and made less errors than Arabic subject (2), is linguistically better. In this regard, it can be suggested that looking at the ratio of the number of words produced to the number of errors made can be a successful measure for students' ability. The next step is to examine the types of errors and their frequencies in the written production. The purpose is to see whether or not these $\mathrm{L}_{2}$ learners suffer from a real deficiency in their knowledge of grammar. We also need to know the most troublesome areas of English grammar, so that language teachers can pay more attention to these areas in their classroom instruction. Consequently, table (4) illustrates the types of errors made by the subjects in the narrative essay and the frequency of each of these errors.

Table (4) shows that while the Arabic subjects have problems with various areas in English grammar, they seem to have particular difficulty in choosing the appropriate tenses. The errors in tenses represent $40.9 \%$ of the total errors made in the Arabic subjects' narrative essays, followed by prepositions (13.6\%) and subject-verb agreement errors (11.4\%). However, we should notice that the high percentage of tenses errors is due to the high number of errors that subjects (5) and (4) made in tenses. This probably implies that $\mathrm{L}_{2}$ learners differ in terms of what can be considered as simple or complex, easy or difficult rules of grammar. Moreover, table (4) shows that the errors made by each language group were in thirteen categories, and although each group made errors in categories different from those of the other group, both groups made errors in seven similar categories. These are (1) tenses, (2) subject-verb agreement, (3) prepositions, (4) nouns, (5) pronouns, (6) missing direct object and (7) articles. For the Spanish subjects, verb morphology seemed to be the most serious problem (33.8\%). Whereas prepositions appeared to be the second troublesome area of grammar for the Arabic group (13.6\%), nouns constituted the second difficult category of errors for the Spanish subjects (14.7\%). Prepositions were the third difficult area for the Spanish subjects (11.8\%), as well as tenses (11.8\%). What is most worth mentioning, here, is that verbs appear to be the most difficult area for the Spanish subjects as a group. This situation is different from that of the Arabic group, in which subjects (4) and (5) contributed most of the errors in tenses, whereas in the Spanish group, the four subjects made errors in verbs. This situation may imply that, verbs could really be a serious problem that requires much attention. (See Brown, 2009; Conley, 2008; Ellis, N., 2005; Ellis, r., 2006; Eslamim and Fatahi, 2008; Hoey, 2007; Jiang, 2007; Kimberly, 2009; Loewen \& Thompson, 2009; Reynolds, 2010; Spada \& Lightbown, 2008).

\subsection{Reasons for Students' Errors}

Based on students' explanations of their errors, the following reasons were repeatedly reported by the Arabic and Spanish subjects: (1) lack of focus on or proper attention to grammar accuracy, which resulted from high rate of speed during writing; (2) students' inability to do more than one thing simultaneously during writing; (3) following or adopting speaking or conversation norms during writing; (4) deficiency in students' knowledge of grammar; (5) students' perceptions of priority in writing, which affected their interest in grammar accuracy; (6) first language interference, particularly Spanish; (7) nature of the writing task itself and, finally, (8) lack of 
practice. The following section is meant to clarify these eight reasons by presenting illustrative samples of students' own explanations.

\subsubsection{Lack of focus on grammar accuracy, resulting from high speed of writing}

S.99. I don't know... really I don't know...maybe because I had to write faster without...

S.105. ... When you write fast, sometimes you don't focus more.

S.770. I think because I was writing too fast.

S.802. Because when I am speaking or writing fast I cannot make the distinction.

S.1152. Just I was in a hurry. I wanted to write first...as I told you before...I think...I only write in the first try but later I can correct the grammar.

Accordingly, in some of his explanations, Arabic subject (4) appeared to be surprised that he made some of his errors; the same reaction that Arabic subject (2) also gave when he was asked to correct his errors:

S.518. This one I should write it right, you know, I don't know why, why, you know, why I didn't write it right...I always use the 's' with the present verb.

R.519. So, why didn't you write it right in the essay?

S.520. I have no idea...I should have it, but, you know, I shouldn't miss this one.

Subject (3) appeared to be surprised when he found that he did not write certain structures correctly "I wrote it in the beginning, he give a telephone number to call'--didn't I write he gave me'?" (Line 363). This is the third case in which subjects seemed surprised of how simple their errors were in the essay.

S.274. I think I thought that I wrote it...I was surprised when I say it in error correction because it is obvious that I hope to be'.

4.2.2 Students' inability to do more than one thing simultaneously (more focus on ideas)

S.488. Grammar!...I was just thinking what I am going to write, then I put everything on the paper according to my thinking, then I did read it again, but I did not catch all this grammar mistakes.

S.1003....because it is difficult sometimes to think of ideas and to think of grammar at the same time...That is the reason; in order to explain ideas very clearly, sometimes you make grammar mistakes.

The above explanations seem to be compatible with two important features within the phenomenon of attention: (1) an individual can attend to only one thing at a time or think only one thought at a time. (2) Attention appears to be serial, in that we appear to attend to or perform first one thing, then another, and we find it very difficult to mix certain activities. That is, the focus of attention is only one place at one time. Consequently, a human who must process information that exceeds his channel capacity will inevitably make errors (Broadbent, 1971).

\subsubsection{Adopting speaking or conversation norms in writing}

S.180. I think because, ah, I rely on the speaking...you know, the conversations, sometimes you don't use.... And I think when you read it "hand shake worth nothing." You know, sounds good.... It is not broken.

S.154. .... because here Americans speaking doesn't use, you know, they don't use the "is," "are" sometimes...I heard a lot of people "they equal nothing"...so I thought it is correct but then I (laughing).

\subsubsection{Deficiency in students' knowledge of grammar}

5.610. I am not very good in past tense and something like had been, especially. I have a problem with it.

S.903. I know the rules but I don't know how to use them because sometimes if I put 'did', I put 'called'... and sometimes if I don't put 'did', called... and sometime if I don't put 'did', I don't put..., you know..., it is like that I still cannot associate what is the auxiliary doing?... or really how you indicate the past or how you indicate the past participle.

The above explanations show that deficiency in students' knowledge of grammar resulted in inaccurate composition writing. And as number 903 above suggests having knowledge of grammar is not an absolute guarantee for successful performance as long as students do not know how to apply it properly. This observation 
provides evidence of the necessity of building our students' conceptual knowledge of grammar and their procedural knowledge, as well.

4.2.5 Students' focus on the meaning, more than grammar accuracy

S.634. ...What I am interested in is the content of the sentence more than how it sounds...

S.757. (silence for 3 seconds) because I was not thinking...I was more interested in the whole story.

S.1170. My problem is when I write in English I don't think...ah...or give attention to grammar. I just write sentences to say what I have in mind. This doesn't mean that grammar is unimportant...not at all, but for me, I pay more attention the ideas first...I want to express my thoughts, but grammar comes in the second time I read my writing...then, I correct my errors.

S.501. The meaning more than the grammar.

All the above explanations bring an issue to the surface; that is, how we can help second language learners focus on both form and meaning at the same time, and what techniques classroom teachers can use to create such a balance between form and meaning (See Bardovi Harling, 2006; Byrnes, 2000; Cohen, 2008; Ellis et al., 2001; Achard, 2007).

\subsubsection{Interference from Spanish}

During the interview, subject (1) blamed her native language for the grammar errors she made in the narrative essay. Subject (1) attributed her error in the subject-verb agreement (the people was) to her native language in which 'people' is singular. In another instance, subject (1) attributed her error in the sentence: "I did not had that much money with me" to her native language:

S.798. ...that is another mistake I always do...I always forget...in Spanish there is not auxiliary in the past; so if you say had' it is already the past, and because we don't use auxiliary even if it is did', I don't realize that did'. I think when I made the sentence I put did' but I don't know that did' is the auxiliary for something else... .

In almost every sentence, subject (1) insisted that she made the grammar errors because of her native language. In addition, subject (2) claimed, during the interview, that one of his errors in the narrative essay was due to interference of Spanish grammar (See Eskildsen, 2008; Farch \& Kasper, 1986; Lightbown \& Spada, 2006; Weijen et al., 2009; Beare \& Bourdages, 2007; Wang, 2003; Knutson, 2006).

S.1041....That was more mechanical translation from Spanish to English...In Spanish, we say "the way how"...so, it was a reflect of the Spanish grammar...but when I read it I felt there is something wrong. In addition, subject (2) blamed Spanish grammar for his errors in the persuasive essay. For example, he wrote in the essay "they encouraged me to continue until to finish the program". Although he eliminated "until" in the unfocused correction task, he attributed his error to Spanish: R.1050. But, why did you write "until" in your essay?

S.1051. The same thing...the influence of Spanish grammar which doesn't correspond to the American grammar.

\subsubsection{Nature of the writing task}

The Spanish subject (2) explained the reasons for making errors as follows:

S.999. (silence for 5 seconds).... I'm not really sure... I was confused in the way part of the narrative is something that happened in the past, but part of the structure is "present" to explain what I was thinking at the moment, even if the action happened in the past... that is the reason of the confusion.

\subsubsection{Lack of practice}

During the interview, the Spanish subject (5) pointed out the reason for making grammar errors, as follows:

S.1420. Because it is difficult for me to think in English..... only in few occasions that I write in English.... Ah.... All my classes in English.... Okay, but I am in history.... Latin American History, my teachers, in general, always address me in Spanish and I go to them to ask them can I write in Spanish?, and they agree because they have excellent Spanish..... but if I have to write in English, I have many friends like Gary and Pedro..... they correct my English....

\section{Cognitive Aspects of Students' Narrative Writing}

Based on the subjects' explanations, it can be argued that narrative writing was some kind of problem solving activity in which the subjects were faced with a difficult or problematic situation. What is at issue, here, is how the subjects approached the narrative assignment, and how they handled the problems that rose to the surface during the production of a narrative text. First, the narrative assignment triggered various reactions; that is, students responded differently to the writing task. In fact, students' explanations show that their reactions were 
constrained by such factors as (1) their prior knowledge of what they were asked to write about, (2) their abilities to activate such knowledge, and (3) their own perceptions of what stories should be. For example, Spanish subject (1) thought of a story that 'would be interesting; a story that would be a kind of unique, special, that wouldn't be boring, or wouldn't be that long and, something [she] could remember very well, that (she] could remember most of the details' (Line:925). Arabic subject (2) thought of 'something bad' that happened to him, as if writing a story is some kind of remembering sad events only; 'in the first stage I didn't think about something good that happened to me' (Line: 301). Other subjects did not feel the need to spend much time in activating or searching for appropriate problems to write about. Rather, they thought only about the first situation they had encountered in the United States, and what it was all about. Arabic subject (3), for example, explained that he did not have to search for a problem to write about, and his first reaction or response to the writing task was thinking of the organization of his essay: how the problem (whatever it is) started, how it ended and how it was solved: 'I tried to organize my paper in these three aspects' (Line: 398 ). This does not mean that he did not have a specific problem in mind. Rather, what this means is that subject (3) already knew what he would write about. Consequently, he did not feel the need to spend time searching for a problem. In other words, it appeared that the writing assignment gave subject (3) the cue to the topic of his essay. In this regard, he pointed out that he chose the transportation system in the U.S.A. to write about because it constituted the first serious problem that happened to him and, it was clear in his mind. That is why it was easy for him to start writing his story. He also indicated that he did not think of the details of his story: S. 400..."I spent, maybe, two minute just thinking about the structure of my writing, but when I was writing I did not think of organizing some ideas that will fill each paragraph because the story just came as a sequence". What is most worth mentioning here is that some of the subjects did have a full and complete plan for their narrative writing including the details that their essays should include. However, the Arabic subjects (4) and (5) talked about having some overall general sense of direction, but not knowing in particular what they would say. Such behavior has been called in the literature 'what next strategy' (Bereiter \& Scardamalia, 1987). On the other hand, other subjects explained that they did not have any plans before starting to write. They were mainly interested in putting on paper what they remembered. The Spanish subject (3), for example, did not even think of organizing her thoughts; rather, she wrote what she remembered. And although memory activation played a vital role in the subjects' narrative writing, it caused some subjects to skip parts of words, articles and to forget to write down words they actually thought of. Also, as the Spanish subject (3) explained, she did not have to elaborate on anything because it was easy [for her] 'to remember what happened' (Line: 1204). Spanish subject (1) pointed out that before she started to write the story, she did not have a specific plan for the structure of the story or how it would look. Rather, she started to recollect the events in terms of their order. And although Spanish subject (2) did not have a specific plan in his mind of how the story would look, he had an idea about some points to develop through the narrative essay: 'I never start writing without to have an idea in my mind of what points I want to write about' (Line:1086). Spanish subject (3) indicated that she did not have any plan or schema in her mind of how the essay would look: 'I didn't know exactly what problem or experience I will be writing on' (Line: 1194). And since she had to write something, she tried to remember everything related to her first arrival in the United States: S.1196...I didn't have a specific problem... I just wrote my experience as it occurred at that time", and S.1200. I just started and I followed what my memory reminds me of what happened...... but I didn't know before I started that I will write these things. Subject (3) indicated that it was easy for her to remember these events: 'because this happened to me and I have these things in my memory, and I will never forget them all my life' (Line: 1198). In addition, she pointed out that she was not concerned with the structure of her story in terms of beginning, middle and end. Rather, she wrote what she remembered: 'I didn't have to elaborate on anything because it was easy to remember what happened' (Line: 1204). Then, for subject (3), writing a narrative essay was just telling what happened as her memory operated during writing: 'I don't really know the rules... I just write'. During the interview, the Arabic subject (4) indicated that when he read the first writing assignment, he immediately thought of a problem he faced in the past, then, he started to recall the events, and, finally, thought of organizing these events and putting them in order. This sequence of actions implies that subject (4) did plan for his narrative essay. However, in terms of the content of his story, subject (4) indicated that he did not have a specific plan for what he would include in his story: he just started writing, relying on his memory: S.532...."sometimes, I write something before something else... that is why I have some kind of problems in writing because, you know, sometimes I have to re-write some sentences because this happened before this or something like that". Drawing on subject (4)'s verbal explanations during the interview, it is clear that his perception of the writing task determined, in part, the quantity of his written production in the narrative essay. For example, his story is remarkably the shortest one. When asked to explain why his story was short, he provided the following explanation: S.550. "Because I am trying just to be as much specific as you asked me to be, you know... I stick myself to your statement in the 
assignment... I put down what you were looking for". Although Arabic subject (5) reacted to the writing assignment as subjects (1), (2) and (4) did, he had his own perception of the writing task, which, consequently, determined the content of his story. That is, although he, first, thought of a problem or experience to write about, he, intentionally, wrote about an experience, not a problem: S.687. "I thought that writing about experience will be.. I can elaborate it more on writing or I can have more information about experience than if I concentrate on a single problem because the experience, I thought, it was more larger than a problem; so I can add or I can think about appropriate things about the experience.... I also wanted to write about something I will have no problem in going through the paper or in the chronical order of the essay". Subject (5) indicated that before starting to write the narrative essay, he had in mind a series of steps to follow': 'I have the major steps in my mind but the details I went through them during writing the story' (Line:699). Moreover, he wrote the story 'very quickly' because 'I remember all these... I went through this experience; I remember everything' (Line: 697). During the interview, the Spanish subject (5) pointed out that she did not plan for her writing; 'she just tried to express her ideas'. And she was not able to write correct sentences while attempting to put the ideas on the paper. She attributed this to two factors: (1) she was unable to think in English and (2) lack of practice. That is, although her academic study is in English, she rarely writes in English because her teachers of Latin American history gave her the permission to write in Spanish. Even if she had to write some papers in English, she tended to rely on her American friends who, at the same time, need her help in Spanish. Moreover, students' explanations suggest that their main problems in writing narrative texts were (1) finding a topic to write about, and (2) starting their essays (opening statements), once topics were found. However, the subjects were able to overcome these two problems by adopting certain strategies. These were (1) a brainstorming process, (2) a memory search for a topic, which resulted in finding one complete problem to write about, pieces of problems, or one's overall experience in the United States, and (3) activation of prior knowledge that appeared pertinent to the writing assignment. Relatedly, students' behaviors during writing the narrative essay lend tentative support to the knowledge-telling model (Bereiter \& Scardamalia, 1987). This model presents writing as a fairly natural task. And although the writing task may have its difficulties, writers can handle them by making maximum use of already existing knowledge structures. As previously explained, the composing process, according to this model, begins with a writing assignment. This model also allows for large differences in outcome depending on the writer's knowledge of the topic and on the writer's sophistication in the literary genre. Analyzing the subjects' explanations shows that their main difficulty during narrative writing was finding a problem to write about, and how to start their essays. Although this was not an easy problem for all subjects, they had ways to handle it and find solutions; either by a brainstorming process or memory search or by activating prior knowledge that appeared to be relevant to the topic. Having succeeded in finding a problem, the subjects appeared to have no problem writing the essay without even stopping to recollect or organize their thoughts. At this stage of the composing process, the subjects appeared to totally rely on their memory and their main task was just telling about the knowledge or the event of their stories. Arabic subject (2) pointed out that it was difficult for him to choose a specific experience or problem to write about, because he had many ideas in his mind, but could not pick up one to be the topic of his story. His difficulty in choosing a problem was, also, due to the fact that he did not encounter 'strong or big bad experience... because I wasn't exposed to many problems'. Consequently, his narrative essay was not, about only one problem; rather, 'it is more than one topic... more than one experience' (Line: 303). Moreover, he pointed out that his major problem in writing the narrative essay was how to start, not only the first paragraph, but also the first sentence of the essay: '... you know, when I finished the first sentence in the first paragraph I felt it is easier than the beginning' (Line:311). When asked to explain why this was difficult for him, subject (2) gave the following explanation: S.313. When you start your essay or paper, you think about different problems.... different ideas... so your mind is like bad radio... too many waves... too many stations at-the same time".

Moreover, he indicated that it was difficult for him to think of ideas for his essay and write grammatically correct sentences. He provided the following explanation: S.292..”we think as foreigners... we think in our own language first and, then, transfer... translate it to English, but sometimes you have in your language hut, sometimes, you have in your language but it is difficult to translate it... that. what makes it difficult... and makes your grammar mistakes appear a lot". Spanish subject (2), also, indicated that it was difficult for him to find a problem or experience to write about, but once he found it, it was easy for him to write down what he wanted. That is, he found it easy to move from one paragraph to another without stopping to recollect his thoughts: S.1090. "... because the idea is one idea, but I developed in one paragraph to another, but if each paragraph has its own idea, this will be difficult ... but when I talked about the same idea, it is a lot easier". His main problem however, was choosing the appropriate tense to express his ideas, 'that I was thinking and feeling something in the past but, at the same time, I have some reflections, ideas came at present' (Line, 1092). He also indicated that it was easy for him to come up with ideas for his essay: however, it was difficult for him to express these ideas 
without making a lot of grammar errors. He also indicated that writing the narrative essay was not 'a big deal' because he had been studying and working at the University for a long time, which had resulted in a lot of reading and writing in English and, consequently, he had become familiar with writing as an activity. He also offered the following justification: S.1098. "my major of political science makes it easy for me to put things together... also, secondly; something personal or experience because you have that experience... you have to remember". Spanish subject (3) indicated that her main problem in writing the narrative essay was how to start it. Moreover, she pointed that her main problem in writing the narrative essay was keeping balance between her thoughts and the speed of her hand during writing. The following is her explanation of this point: S.1210. "maybe my thoughts are faster than my writing... if I am not so fast, maybe I could pay attention to the organization... maybe, as we used to say, to put more flowers... to make the composition more nicely." In contrast to subject (3), the Arabic subject (4) indicated that his main problem in writing the narrative essay was 'the opening statement'. In this regard, he gave the following explanation: S.536.... how I will write it down... should I start this way, or this way or that way and how will I write it down... I know what happened in the first, but what I start with; that is my problem".

Having decided on his opening sentences, subject (4) pointed out that he had no problem developing his thoughts because 'it wasn't hard to recall' (Line: 538). At this point, he became concerned more with putting the events in order and in writing grammatically correct sentences: S.538. ... "here I know what I am going to write and then start thinking how I am going to write it down in a good English... that is my problem". Finally, the Arabic subject (5) indicated that he had no problem recalling all the events related to his story. His main problem, however, was how to organize his story: S.691. "... I had many things in my mind related to this experience; so where to start?... so, I decided to write from I got the approval from the committee". Spanish subject (1) indicated that she did not have any problem writing the narrative essay and, she explained the reason as follows:" S.933. ".......Because... because I had very clear in my mind what was the story I want to write about. I could recall it very easily... so, I didn't have any problem". Furthermore, she pointed out that she thought of how she would start the story and, that is why she created, in her introductory sentence, what she called 'the context', 'where this story is occurred: when this happened, and how this happened' (Line: 933). However, when she was trying to recall the events of her story during writing, she had to skip parts of words, articles and, she was unable to write down words she actually thought of. As she explained, 'the process of thinking is much faster than the hand in writing' (Line: 935). It was however; easy for her to move from one idea to another because writing the story was a matter of just putting on paper what she recalled. That is, writing and recalling are one thing: it is not like you are recalling or writing two different events that are not related to one another' (Line: 939). Consequently, she did not stop writing until she finished her story. She then reviewed what she had written but did not change anything: 'I thought I said the story I wanted to tell' (Line: 941).

\section{Cultural Aspects of the Arabic Students' Narrative Writing}

Analyzing the Arabic subjects' explanations of their native culture's effect on their narrative writing indicated that most of the effect is attributable to the Arabic language. For example, Arabic subject (1) indicated that Arabic affected his choice of the topic he wrote about, the ideas he included in the essay and the style of his narrative essay. More interestingly, he pointed out that he was consciously aware of the interference of his native language, and allowed it to happen on purpose. Subject (2) also indicated that his native language added 'beauty' to his narrative essay. However, this made him use certain expressions that may sound good, but at the expense of the meaning of the whole structure. Arabic subject (3) pointed out that because of Islamic beliefs that call for mutual trust among people; he did not try hard enough to work on his ideas. In addition, he seemed to be angry at the educational system of his native country. Arabic subject(4) explained that he tended to repeat some structures or sentences as a habit inherited from his writing in the native language. He also admitted that although he had been in the U.S.A. for a long time, he could not help thinking and translating from his native language to English. Finally, Arabic subject (5) totally denied any effect of his culture on his narrative writing of the narrative essay. The following is a discussion of the Arab students' explanations of how their culture affected their narrative writing.

\subsection{Choice of the Topic}

In their attempts to choose a topic for their narrative stories, some subjects appeared to resort to their native culture as a source of knowledge. It may be easy for them to write about something that is related to their life and traditions: S.56. "The greeting kiss itself is an Arabic theme... we Arabs are obliged to kiss each other when we greet each other and when I came here it was so odd to them... I was trying to kiss them and they were reluctant to do so". 


\subsection{Rhetorical Style / Ideas}

The Arabic language, an inseparable component of the subjects' native culture, appeared to affect the ideas that the subjects used in their stories. As one of the subjects explained, Arabic is a metaphoric language, and he could not get rid of this aspect in his writing in English: 'no matter how good it is some flavor of Arabic would be included in my English writing, especially metaphors and similes' (Line:42): S.42. ... my lips were so warm and desperate for a kiss on their cheeks...their cheeks were blushing as if it were their first time; and, S.44. ... in Arabic things that are dead but are not alive can be brought to life by a way of similes and metaphors and this, I think, is affecting my English writing. Some of the Arab subjects demonstrated sensitivity to cultural conventions, and used them strategically: S.46. ... "as long as the ideas are clear, the grammar is correct... the ideas will be conveyed safely to the nonnative speakers, even if this type of stylistics or similes is not in their own language".

When asked about the effect of his culture on his narrative essay, subject (2) pointed out that his Arabic culture added 'some beauty' to his writing of the narrative essay. However, from his verbal explanations, one can say that his culture affected his writing of the narrative essay negatively, because he tends to use words and expressions that may have a degree of beauty and eloquence in his native language, but do not fit the context in English. This observation appears to be compatible with the results of a study on thirty Arab students at Indiana University (El-daly, 1986: 51) Specifically, it was found that "In their written production, specialized students [in linguistics] tried to demonstrate their mastery of English by choosing expressions which may sound good enough, but they did not fit their contexts. In other words, they focused on the form at the expense of the pragmatic function of language". More interestingly, subject (2) indicated that adopting his native culture's threads of thinking is absolutely good. This explanation is based on his own belief that the Arabic or Islamic culture is very strong and, accordingly, he could not create his identity in a different culture, or change his own identity 'like the snake who changes its skin' (Line: 331 ).

\subsection{Translation From $L_{1}$}

Arabic subject (2) indicated that, during his writing of the narrative essay, he tended to think in his native language. Specifically, he felt that he was translating the events that involved his Arab friends and his wife: S.319 ... "everything happened to me almost in Arabic... so, it is hard to think in different language and then try to translate it to another language." Furthermore, he pointed out the following: 'you try to structure sentences or paragraphs it is easier to structure it by your own language' (Line: 323). Subject (4) indicated that although he had been in the United States for a long time, he still had to 'go through transition between thinking and how you will it in language, you know, because it is not your language' (Line: 540). More interestingly, subject (4) pointed out that although he tried to think in English during writing the narrative essay, he could not help thinking in his native language: 'all your memory in a different language... you cannot change it' (Line: 542). Later on, subject (4) provided the following explanation: S.544. ... "you know, probably, I was thinking in Arabic in this way I write it down the way I am thinking in Arabic that is why it came differently". In fact, subject (3) explicitly indicated that his native language affected his writing of the narrative essay, as follows: S.408... "I know the rules, the structures, grammar and the nature of writing in English but I cannot take myself out of the influence of my native language... that is my understanding... sometimes it is hard to write in English... sometimes I got lost".

When asked about whether his native language affected his writing of the narrative essay, the Arabic subject (5) provided a rather interesting explanation. For him, the process of thinking whether in Arabic or English is something and the act of writing is something else. For him, consequently, although he was thinking in his native language, this did not affect, in any way, his written production, because he was writing in English, not Arabic: S.701.... I think in Arabic but there is no difference in thinking in Arabic and in English... but the next step is to write about these thoughts... the writing is in English... but there is, I think much influence about the thinking, but in writing it is all English". Later on, subject (5) elaborated further on this issue when he denied the possibility of structuring his sentences, first, in Arabic and, second, translating them to English. He provided the following explanation: S.703. ... I didn't translate from language to language, but I think in my mind before I start any idea in Arabic... this is the thinking, but when I start to write I write in English. I didn't try the sentence in Arabic and then translated to English. I used pure English".

Arabic subject (4) indicated that if he were to write the same narrative story in his native language, it would not significantly differ from the one he wrote in English. The only difference, however, would be that his story in Arabic would not have such a number of grammar errors. The following is his verbal explanation: S.540. “.... because I am going to recall and write the same while I am thinking it will not be any difficult for me because I 
know all the grammar of my native language and everything". Subject (5) pointed out that if he were to write a similar story in his native language, it would differ from the one he wrote in English. Drawing on his verbal explanation, the differences would be linguistically - oriented. That is, because he is fluent in Arabic, his story in Arabic would be clean from grammar errors: S.707. “... I am fluent in Arabic; this means that I can write very good sentences without any mistakes... because in English, as I said, I have some problems in the tenses, some parts of the English language, but in Arabic I have no such problems because when I write in Arabic it is easy". In terms of organization and the overall structure of the story, subject (5), also, pointed out that his story in Arabic and English will be different. Drawing on his verbal explanations during the interview, one can argue that this difference is mainly due to the level of competence in both languages, which is, naturally, higher in Arabic than it is in English S.71. "In Arabic, if I want to write a story about experience, I control the language; so I can put an introduction better than the one I put here in the English essay; I can use many phrases better than the ones I used in this essay. I mean give them a very nice look for the reader, because many words I can remember in Arabic, but not the same as in English......".

\subsection{Arabic Educational Systems \& Insufficient Writing Instruction}

Arabic subject (3) pointed out that his native culture affected his writing in English in two ways: (1) because all Arab students have one type of audience who share their ideas, thoughts and Islamic beliefs, they tend not to work hard 'to support their ideas'. (2) Arab students did not learn to write in Arabic and/or English: 'I don't believe that Arabs try to write in a certain way... we are taught nothing' (Line: 416).

S.456. ... in writing we don't think of organizing our papers... just write something... I mean in home we say this is writing... that is not important... as a result we are not good either in Arabic or English.

From the above explanations, one can perceive that subject (3) was furious and angry at the educational systems in Arab states: S.416. "... although I know the structure and style of writing in English, but since I have not been trained to do so, I have difficult time to write in English... if I have been trained I could be writing a lot better".

\subsection{Repetition}

Arabic subject (4) indicated that the only way in which his native culture affected his writing of the narrative story was that he, as all Arabs, repeated some statements more than once. What he meant by this is represented in the sentence 'I asked him how much I am going to pay him'. In fact, the repetition of 'him' is mainly due to interference from Arabic grammar.

Arabic: Ana sa?ltuhu kam sa?dfaluhu

English: I asked-him how much will pay-him?

'I asked him how much I am going to pay him'.

Consequently, it seems that the cultural effect is represented only in his native language's influence on his writing. In this regard, subject (4) gave the following explanation: S.554. “... culture affects the language, you know, but the culture itself, I could adjust myself to the culture, you know, I have been here for almost four years... then, I know how the people think, how the people talks, how the people put their, even, ideas on the paper, but not as perfect as them".

\section{Cultural Aspects of the Spanish Students Narrative Writing}

Based on the subjects' explanations, it seems that there is no consensus among the Spanish subjects regarding the effect of the Latin American culture on their narrative writing. Although Spanish subject (1) indicated that both Spanish and American cultures are similar, subject (2) indicated that they are different. Their different perceptions controlled their beliefs about their own cultures as a factor of shaping their narrative written productions. Spanish subject (1) indicated that her native culture affected her choice of the topic, which represents the emotional side of her character. Also, her native language interfered in forming many of her English grammar structures. Subject (2) indicated that his native language did not affect his narrative writing because he wrote about something personal, and relied on what he remembered. However, Spanish grammar interfered in structuring many of his English sentences in the narrative essay. In addition, subject (3) denied totally any effect of her native culture on her writing, whereas subject (4) indicated that her culture affected her choice of the story she wrote about, without feeling any shame of writing about something that may seem stupid. However, she did her best not to sound as a Spanish speaker. That is, she tried not to reveal her identity through writing. The following is a discussion of the Spanish subjects' explanations of how their native culture affected their narrative writing. 


\subsection{Divided Opinion about the Effect of Culture on Writing}

Spanish subject (1) pointed out that Spanish culture does not significantly differ from the American culture and, accordingly, Spanish culture does not affect her writing of the narrative essay: S.949. “ ...Spanish culture and American culture are different, but these differences are not huge differences... I mean, you will still be speaking about the western mentality... western ideology... Spanish culture is part of the European model. ... almost everything in Spanish and English and any Romance language is the same”. Regarding Latin American culture's effect on his writing of the narrative essay, Spanish subject (2) indicated that 'the person is conditioned by the question and the topic' and his choice of the problem he wrote about was influenced by his culture, which differs from the American culture.

\subsection{Choice of the Topic}

Subject (1) did not deny the fact that being a Latin American, she sees things more emotionally and, as she pointed out, this is part of her culture. And, that is why she chose this particular story to write about: 'this story means a lot of value to me' (Line: 951):

S.953. The whole story has a lot of meaning to me because it was nice... it was nice to find a woman who was willing to help a stranger, that is the normal in my country.

S.957. ... the story means a lot to me because of my background... I give big value to it because of my culture... so, the story is of great value because of my own values and culture.

As Spanish subject (4) explained, the Spanish people are not ashamed to express what they feel, whereas Americans are not willing to talk about something 'in which they will look stupid to the reader' (Line:1270). Subject (4), further, added the following: We don't care... we like to have fun... I mean, we tell what happened to us, and that is when asked if she can cite an example from her story to illustrate the influence of her culture on her writing, she referred to the incident in which her Latin American group reacted 'stupidly' to earthquakes: 'I guess that is part of my culture... Japanese may react the same way as we did; Americans wouldn't' (Line:1272).

\section{$7.3 L_{1}$ Interface}

Subject (1) indicated that her native language affected the way she structured the sentences but, it did not affect the ideas or the overall organization of her story: S.943. ... "but I did recall the story in English, because I was writing in English". Later on, subject (1) explained her rationale as follows: S.947. ... "if you are thinking in Spanish, you say it perfectly well in Spanish... if you are thinking in English, you say it in English... the meaning gets through, but you don't pay much attention to grammar... because what is important is the meaning... if you get through with the meaning, , this means that you are, at least the way I feel it, I'm thinking in English and I'm saying this in English". Subject (1) indicated that if she were to write the same story in her native language, there would not be any difference between her story in English and the one in Spanish: S.943. “.... in writing this story I just sat down and I remembered and I wrote what I remembered... in Spanish if I want to write something like this... I will sit and write what I remembered... the sane way I did in English". Although subject (2) admitted that Spanish sometimes interfered in his writing of the narrative essay, he indicated that Spanish did, not have such a big effect on him 'because this is personal and writing about experience... you write what you remember' (Line:1102). Therefore, as he explained, he did not 'make mechanical translation from Spanish sentences to English but... there is some reflections from Spanish grammar. Sometimes, aspects of Spanish grammar interfered' (Line:1104). Subject (2) indicated that if he were to write such a story in Spanish, there would not be a big difference between his essay in Spanish and the one he wrote in English. The only difference, according to subject (2), would be that his story in Spanish would not contain as many errors as the one in English. Spanish subject (3) indicated that if she were to write such a story in Spanish, she would use the English style; not the Spanish one. She demonstrated understanding of the differences between both styles: 'in Spanish we use long sentences.., we use more long sentences and not more specific... but when I write in English I don't do that; I try to be more specific' (Line:1212). With this in mind, she added that when she writes to a Spanish friend or someone who speaks Spanish, she uses the same structure '... short sentences... short paragraphs'. Consequently, she felt that if she were to write the narrative essay in Spanish, her essay would not differ from the one she wrote in English. When asked to explain how she can follow the English style of writing although her native language is Spanish, she could not explain the factors that helped her to accomplish this: 'I don't really know... I just notice that, maybe because I write a lot in English and I read a lot too... I don't know how I reached this'. Spanish subject (5) indicated that if she were to write a similar story in Spanish, she would be able to elaborate more on her ideas and the essay would be more political: 'Because I have another feelings in respect to the United States I cannot express in the English'. 


\subsection{Identity}

Subject (4) indicated that she is always aware that her native language, sometimes, interferes in her writing in English, but she tries to avoid it as much as possible. To accomplish this, she tended to think in English: 'and whenever I noticed that my sentence was basically a reflection of Spanish, I changed my sentence. I am always aware when I am writing' (Line: 1276). More important is the reason that subject (4) tried not to sound as a Spanish speaker: S.1278. “... Spanish speakers have the most Hispanic stigma in this culture. But it depends on from where you came. You from Spain, you, then, have the highest status... if you come from Argentina, you have the second rank, if you came from central America, you will have the lowest status... so being Hispanic is not something good... so, I tried not to show that I was Hispanic in my writing". This means that some of the Spanish subjects tried not to reveal their cultural identity in writing. The Arabic subjects, however, did not have any problem revealing their identities. This does not mean that the Arabic subjects are more proud of their culture than the Spanish subjects; rather, it may be due to the fact that all the Arabic subjects were males, and the Spanish subjects, except subject (2), were females. This may be a gender characteristic more than it is a cultural one.

\section{Conclusion}

This study was undertaken to investigate the written performance of ten foreign students at the University of Pittsburgh. They belonged to two different linguistic and cultural backgrounds. The first was from the Arabic language group, and the second was from the Spanish linguistic group. Analyzing the data may motivate us to make specific conclusions.

First, within and across the two language groups, students' written productions were not quantitatively correlated to the number of their errors. That is, it was not necessarily the case that the more an individual wrote, the more errors that he/she made. Second, some subjects were able to produce many words without making any grammar errors, such as Arabic subject (1) and Spanish subject (4). Other subjects were able to produce a fairly good number of words with the least number of errors, such as Arabic subject (3). Other subjects produced the least number of words but made the highest number of errors such as Spanish subject (5). The above finding implies that assessing second language learners' performance in writing is not an easy task. Relying only on the number of words produced in composition writing may not be an accurate or valid measure of students' linguistic abilities. For example, it may not be reasonable to suggest that Arabic subject (2), who produced 524 words in his narrative essay, is linguistically better than Arabic subject (3) who produced 473 words. The number of words only tells us that subject (2) was able to write more than subject (3), but it does not tell us anything about how accurate his writing was. In addition, relying only on the number of errors made in composition writing may not be a valid measure for students' linguistic abilities. That is, making the least number of errors in composition writing does not necessarily mean that the student-writer is linguistically competent, or vice versa. The point, here, is that we need to consider students' performance from more than one perspective. In addition to the number of words produced and the number of errors made, we need to consider an additional measure. We need to examine the ratio of the number of words to that of the errors. Students' proficiency in writing should encompass both elements of fluency, represented in students' ability to demonstrate facility in producing language; (i.e. total number of words) and accuracy, represented in students' ability not to make errors. For example, the ratio of the Arabic subject (2)'s number of words to that of his errors is $35: 1$, while that of the Arabic subject (3) is 84:1. This means that subject (3) was a more proficient writer than subject (2).

The qualitative analysis of the data showed that there are many reasons for students' errors, in addition to students' incomplete knowledge of grammar. Two of the major reasons are (1) the complexity of writing in a second language; therefore, students were unable to do more than one thing simultaneously during writing, and (2) students' focus on the meaning and generating ideas rather than grammar accuracy. Based on the subjects' explanations during the interview, one can argue that writing in a second language is a multidimensional activity which requires $\mathrm{L}_{2}$ learners to do more than one thing simultaneously. In this regard, I argue that the attention theory, as explained by cognitive psychologists, may provide us with a reasonable and plausible perspective of students' performance. Two important features within the phenomenon of attention have been identified: (1) an individual can attend to only one thing at a time or think only one thought at a time. (2) Attention appears to be serial, in that we appear to attend to or perform first one thing, then another, and we find it very difficult to mix certain activities. That is, the focus of attention is only on one place at one times. S.1003 ...because it is difficult sometimes to think of ideas and to think of grammar at the same time...that is the reason; in order to explain ideas very clearly sometimes you make grammar mistakes. The above quotation suggest that students' errors are due, in part, to their inability to do two things at the same time: coming up with ideas and watching for grammar errors. Instead, they tried to think of ideas and put them on the paper, and then they may be able to check the 
accuracy of their structures. This suggests that attention must be devoted to each component of the writing activity. At the same time, however, we must accept the fact that beginning attempts at such multidimensional activity are often slow and error-prone.

The results of this study seem to support Perl's findings regarding the behavior of students writers. Specifically, Perl found that both skilled and unskilled writers discover their ideas in the process of composing. Composing, as described by some of the subjects, seems to be a process of discovery, exploring ideas and presenting them in the best way possible. It is creative and may not be based on a clear sense of direction or explicit plan. It is true that some of the subjects indicated that they had a specific plan before writing their essays; however, their plans were not static but rather dynamic, that is, it allows for further discovery and exploration. In other words, the subjects of this study seemed to experience writing as a process of creating meaning. Rather than knowing from the outset what is it they will say, these students explore their ideas and thoughts on paper, discovering in the act of doing so not only what these ideas and thoughts are, but also the form with which best to express them. Moreover, the composing behaviors of both Arabic and Spanish speakers appeared to correspond to what the knowledge-telling model says. Based on the subjects' explanations, it is clear that writing narrative texts was a matter of just telling about the knowledge or the events of their stories. Relatedly, their main concern in writing the narrative essay was to find a problem, and once this problem was found, all subjects explained that they did not have any problem putting ideas on paper. However, there was no interaction between text processing and knowledge processing, as the knowledge-transforming model maintains. That is, neither students' writing nor their knowledge had been developed as a result of a lack of interaction between the process of writing and students' existent knowledge.

In addition, the composing behaviors of the subjects do not totally support Flower and Hayes' (1980) model of writing. Specifically, in terms of planning not all subjects planned for their writings. Those who planned for their writings were of two types: (1) some of the subjects did have a full and complete plan for their writing, including the details that their essays should include, (2) other subjects did have a general sense of direction, without knowing in particular what they would say. Bereiter and Scardamalia (1987) called such behavior "what next strategy." Some other subjects explained, however, that they did not have any images, proposition or feelings of knowledge to be used in writing. Rather, they wrote what they remembered; one event after the other. The Spanish subject (3), for example, did not think of organizing her thoughts and, as she said, she did not have to elaborate on anything because it was easy for her "to remember what happened." In addition, the only mental process that was identified by Flower and Hayes, and also found in the subjects' behavior was the process of "translating," which is defined as the process of turning ideas into written language. However, the two mental processes "reviewing" and "monitoring," as defined by Flower and Hayes, were never reported by the subjects except the Arabic subject (1) and the Spanish subject (4).

Analyzing the Arabic subjects' explanations of their native culture's effect on their narrative writing indicated that most of the effect is attributable to the Arabic language. For example, one of the Arabic subjects indicated that Arabic affected his choice of the topic he wrote about, the ideas he included in the essay and the style of his narrative essay. More interestingly, he pointed out that he was consciously aware of the interference of his native language, and allowed it to happen on purpose. Another subject also indicated that his native language added 'beauty' to his narrative essay. However, this made him use certain expressions that may sound good, but at the expense of the meaning of the whole structure. Arabic subject (3) pointed out that because of Islamic beliefs that call for mutual trust among people, he did not try hard enough to work on his ideas. In addition, he seemed to be angry at the educational system of his native country. Arabic subject (4) explained that he tended to repeat some structures of sentences as a habit inherited from his writing in the native language. He also admitted that although he had been in the U.S.A. for a long time, he could not help thinking and translating from his native language to English. Finally, Arabic subject (5) totally denied any effect of his culture on his narrative writings. In addition, based on the subjects' explanations, it seems that there is no common theme among the Spanish subjects regarding the effect of the Latin American culture on their narrative writing. Although, Spanish subject (1) indicated that both Spanish and American cultures are similar, subject (2) indicated that they are different. Their different perceptions controlled their beliefs about their own cultures as a factor of shaping their narrative written productions. Spanish subject (1) indicated that her native culture affected her choice of the topic, which represents the emotional side of her character. Also, her native language interfered in forming many of her English grammar structures. Subject (2) indicated that his native language did not affect his narrative writing because he wrote about something personal, and relied on what he remembered. However, Spanish grammar interfered in structuring many of his English sentences in the narrative essay. Moreover, subject (3) denied totally any effect of her native culture on her writing, whereas subject (4) indicated that her culture affected her 
choice of the story she wrote about, without feeling any shame of writing about something that may seem stupid. However, she did her best not to sound like a Spanish speaker. That is, she tried not to reveal her identity through writing. During the interview, the Spanish subjects demonstrated what can be called 'cultural competence'. That is, they were aware of their native culture's ways of thinking as well as those of the target language. Moreover, based on the Spanish subjects' explanations, it seems that the Spanish culture's effect was constrained by such factors as the subjects' perceptions of their own culture, and the target culture, as well. It seems that the Spanish subjects tended to intentionally disreveal their identities as Hispanic. This is not to suggest that the Spanish subjects were not proud of being Hispanic. Quite the contrary, they demonstrated a great loyalty to their own native culture. But, they seemed to be concerned about other people's opinions of them and their culture. So, to play it safe, they tended to disreveal their identity.

In conclusion, this study suggests that writing in a second language involves three interrelated skills: linguistic, cognitive, and cultural. Regardless of language proficiency, students also need to master the essentially non-linguistic intellectual and cognitive skills which underlie writing.

\section{References}

Achard, M. (2007). Usage-based semantics: Meaning and distribution in three French "breaking" verbs. Studies in Languages, University of Joensuu, Vol. 41.

Arapoff, N. (1967). Writing: A thinking process. TESOL Quarterly, 1(2), 33-39. http://dx.doi.org/10.2307/3585751

Bardovi-Harlig, K. (2006). On the role of formulas in the acquisition of $\mathrm{L}_{2}$ pragmatics. Pragmatics and Language Learning, Vol. 11, Honolulu, University of Hawaii.

Beare, S. \& Bourdages, J. (2007). Skilled writers' generating strategies in $\mathrm{L}_{1}$ and $\mathrm{L}_{2}$ : An exploratory study. In G. Rijlaarsdam (Series Ed.), M. Torrance, L. Van Waves \& D. Galbraith (Eds.), Studies in Writing, Vol. 20, Writing and Cognition Research and Applications (pp. 151-161). Amsterdam: Elsevier.

Beare, S. \& Bourdages, J. (2007). Skilled writers' generating strategies in $\mathrm{L}_{1}$ and $\mathrm{L}_{2}$ : An exploratory study. In G. Rijlaarsdam, M. Torrance, and L. Van Waes (Eds.), Studies in Writing, Vol. 20. Amsterdam.

Bialystok, E. (1981). The role of linguistic knowledge in second language use. Studies in Second Language Acquisition, 4(1), 31-45. http://dx.doi.org/10.1017/S0272263100004265

Bialystok, E. (1982). On the relationship between knowing and using linguistic forms. Applied Linguistics, 3, 181-206. http://dx.doi.org/10.1093/applin/3.3.181

Bitchener, J. \& Bastukman, H. (2006). Perception of the difficulties of post graduate $\mathrm{L}_{2}$ thesis students writing the discussion section. Journal of English for Academic Purposes, 1-15.

Blanton, L. (1987). Reshaping ESL students' perceptions of writing. ELT Journal, 41/2.

Boughey, C. (1997). Learning to write by writing to learn: a group-work approach. ELT Journal, 51/2. http://dx.doi.org/10.1093/elt/51.2.126

Boyer, E. (1983). High School. New York: Harper and Row.

Braaskma, M., Rijlaarsdam, G., V. Bergh \& Van-Hout, B. (2004). Observational learning and its effects on the orchestration of writing process. Cognition and Instruction, 22, 1-36. http://dx.doi.org/10.1207/s1532690Xci2201_1

Broadbent, D.E. (1971). Decision and Stress. London: Academic Press.

Brown, A. (2009). Students' and teachers' perceptions of effective foreign language teaching: A comparison of ideals. The Modern Language Journal, 93, 46-60. http://dx.doi.org/10.1111/j.1540-4781.2009.00827.x

Buckingham, T. (1979). The goals of advanced composition instruction. TESOL Quarterly, 13(20), 241-254. http://dx.doi.org/10.2307/3586213

Byrnes, H. (2000). Meaning and form in classroom-based SLA research: Reflections from a college foreign language perspective. (pp. 125-179). In J.F. Lee and A. Valdman (eds.), Meaning and Form: Multiple Perspectives. Boston: Heinle and Heinle.

Canagarajah, S. (2002). The geopolitics of academic writing and knowledge production. Pittsburgh, PA.

Casanave, C. (2004). Controversies in second language writing: Dilemmas and decisions in research and instruction. Ann Arbor: The University of Michigan Press. http://dx.doi.org/10.1111/j.1473-4192.2004.00052.x 
Centeno- Cortes, B. \& Jienez, A. (2004). Problem Solving tasks in a foreign language: The importance of the $\mathrm{L}_{1}$ in private verbal thinking. International Journal of Applied Linguistics, 14: 7-35.

Chenoweth, N. \& Hayes, J. (2001). Fluency in writing. Generating text in $\mathrm{L}_{1}$ and $\mathrm{L}_{2}$. Written Communication, 18(1), 80-98. http://dx.doi.org/10.1177/0741088301018001004

Cohen, A. (2008). Strategy instruction for learners of Japanese: How do you do it and what's in it for them? Japanese as a foreign language education: Multiple perspectives (pp. 45-60). Tokyo: Kurosio Shuppan.

Collins, A. \& Gentner, D. (1980). A framework for a cognitive theory of writing. In Gregg, L. and Steinberg, E. (eds.), Cognitive processes in writing. Hillsdale, NJ: Erlbaum.

Conley, M. (2008). Cognitive strategy instruction for adolescents: What we know about the promise, what we don't about the potential. Harvard Education Review, 78(1), 84-106.

Connor, U. (2002). New directions in contrastive rhetoric. TESOL Quarterly, 36(4), 493-510. http://dx.doi.org/10.2307/3588238

Connors, R. (1997). Composition-rhetoric: Backgrounds, theory, and padagophy. Pittsburgh, PA.

Coombs, V. (1986). Syntax and communicative strategies in intermediate German composition. Modern Language Journal, 70, 114-124. http://dx.doi.org/10.1111/j.1540-4781.1986.tb05253.x

Cooper, C. \& Greenbaum, S. (1988). Preface. In Purves, A. (ed.), Writing across languages and issues in contrastive rhetoric. Sage Publications, Inc.

El-dali, H. (2010). Second language learners' metalinguistic ability and classroom instruction: Focus on grammaticality judgements. Journal of Language and Literature, 56, 46-62.

El-daly, H. (1986). An analytical study of the syntactic errors of Arab students in the skill of writing in English. Master's Thesis, Bloomington, IN.

Ellis, N.C. (2005). At the interface: Dynamic interactions of explicit and implicit language knowledge. Studies in Second Language Acquisition, 27, 305-352. http://dx.doi.org/10.1017/S027226310505014X

Ellis, R. (2006). Current issues in the teaching of grammar: An SLA perspective. TESOL Quarterly, 40, 83-107. http://dx.doi.org/10.2307/40264512

Ellis, R., Basturkmen, H. \& Loewen, S. (2001). Preemptive focus on focus in the ESL classroom. TESOL Quarterly, 35(3), 407-432. http://dx.doi.org/10.2307/3588029

Emig, J. (1971). The composing processes of twelfth graders. Urbana, IL: National Council of Teachers of English.

Eskildsen, S. (2008). Constructing another language - usage-based linguistics in second language acquisition. Applied Linguistics, Oxford University Press, 1-23.

Eslamim, Z. \& Fatahi, A. (2008). Teachers' sense of self efficacy, English proficiency, and instructional strategies. A study of nonnative EFL teachers in Iran. TESL-EJ, 11(4).

Ferris, D. \& Hedgcock, J. (1998). Teaching ESL composition: purpose, process, and practice. Mahwah. NJ.

Flower, L. \& Hayes, J. (1980). The dynamics of composing: Making plans and juggling constraints. In Gregg, L. and Steinberg, E. (eds.), Cognitive process in writing. Hillsdale, NJ: Erlbaum.

Flower, L. \& Hayes, J. (1983). A cognitive model of the writing process in adults. Pittsburgh, PA: Carnegie Mellon University.

Gass, S. (1983). The development of $\mathrm{L}_{2}$ intuitions. TESOL Quarterly, 17(2), 273-291. http://dx.doi.org/10.2307/3586654

Gass, S. and Mackey, A. (2011). The Routledge handbook of second language acquisition. Routledge, Taylor \& Francis Group.

Grabe, W. (2001). Notes towards a theory of second language writing. In Silva, T. \& Matsuda, P. (Eds.), On Second language writing. Mahwah NJ: Lawrence Erlbaum.

Graffield, Vile, N. (1998). Creative writing in the ETL classroom. Modern English Teacher, 7(3).

Gregorious, C. (2011). Language, ideology and identity in serial killer narrative. Routledge, Taylor \& Francis Group.

Hairston, M. (1982). The winds of changes: Thomas Kuhn and the revolution in the teaching of writing. College 
Composition and Communication, 33(1), 76-88. http://dx.doi.org/10.2307/357846

Heath, S. (1983). Ways with Words. New York: Cambridge University Press.

Hinkel, E. (2004). Teaching academic ESL writing: Practical techniques in vocabulary and grammar. Mahwah, NJ: Elbaum Associates.

Hinkel, E. (2011). Handbook of research in second language teaching and learning, Vol. 2. Routledge, Taylor \& Francis Group.

Hirose, K. (2003). Comparing $\mathrm{L}_{1}$ and $\mathrm{L}_{2}$ organizational patterns in the argumentative writing of Japanese EFL students. Journal of Second Language Writing, 12(2), 181-209. http://dx.doi.org/10.1016/S1060-3743(03)00015-8

Hoey, M. (2007). Grammatical creativity: A corpus perspective. In Hoey, M., Mahlberg, M., Stubbs, M. and Teubert, W. (eds.). Text, Discourse and Corpora. London, Continuum.

Hua, Z. (2011). The language and intercultural communication reader. Routledge, Taylor \& Francis Group.

Hughey, J., Wormuth, D., Hartfiel, V. \& Jacobs, H. (1983). Teaching ESL composition: Principles and teaching. Rowley, MA: Newbury House Publishers, Inc.

Hull, G. (1989). Research on writing: Building a cognitive and social understanding of composing. In Resnick, R.B. and Kloofer, L.E. (ed.), Toward the thinking curriculum: current cognitive research. Alexandria, VA.

Jiang, N. (2007). Selective integration of linguistic knowledge in adult second language learning. Language Learning, 57(1), 1-33. http://dx.doi.org/10.1111/j.1467-9922.2007.00397.x

Kaplan, R. (1966). Cultural thought patterns in intercultural education. Language Learning, 16, 1-20. http://dx.doi.org/10.1111/j.1467-1770.1966.tb00804.x

Kellogg, R. (1996). A model of working memory in writing. In C. Levy \& S. Ransdell (Eds.). The Science of Writing: Theories, Methods, Individual Differences and Applications (pp. 57-71). Mahwah, NJ: Lawrence Erlbaum.

Khaldieh, S. (2000). Learning strategies and writing processes of proficient vs. less-proficient learners of Arabic. Foreign Language Annuals, 33(5), 522-534. http://dx.doi.org/10.1111/j.1944-9720.2000.tb01996.x

Kimberly, A. (2009). Adult learners' perceptions of the incorporation of their $L_{1}$ in foreign language teaching and learning. Oxford University Press.

Knutson, E. (2006). Thinking in English, writing in French. The French Review, 80(1), 88-109.

Krashen S. (1987). Principles and practice in second language acquisition. Prentice Hall International.

Lee, S. (2005). Facilitating and inhibiting factors in English as a foreign language writing performance: A model testing with structural equation Modeling. Language Learning, 55(2), 335-374. http://dx.doi.org/10.1111/j.0023-8333.2005.00306.x

Lightbown, P.M. \& Spada, N. (2006). How Languages are Learned ( $3^{\text {rd }}$ ed.). Oxford: Oxford University Press. Lillis, T. and Curry, M. (2011). Academic writing in a global context. Routledge, Taylor \& Francis Group.

Lindemann, E. (2001). A rhetoric for writing teachers. New York: Oxford University Press.

Locke, T. (2011). Beyond the Grammar Wars. Routledge, Taylor \& Francis Group.

Loewen, S., Li, S. \& Thompson, A. (2009). Second language learners' beliefs about grammar instruction and error correction. The Modern Language Journal, 93, 91-104. http://dx.doi.org/10.1111/j.1540-4781.2009.00830.x

Mamba, M. (2010). Thematic based writing: Beyond a matrix model. Paper presented at the Tenth Annual ELT Conference, Sultan Qaboos University.

Martinez, I. (2005). Native and non-native writers' use of first person pronouns in the different sections of biology research articles in English. Journal of Second Language Writing, 14(3), 174-190. http://dx.doi.org/10.1016/j.jslw.2005.06.001

Matsuda, P. (2003). Second language writing in the 20th century: A situated historical perspective. In B. Kroll, (Ed.), Exploring the dynamics of second language writing. New York, NY: Cambridge University Press.

$\mathrm{Mu}, \mathrm{C}$. \& Carrington, S. (2007). An investigation of three Chinese Students' English writing strategies. TESL-FL, 11(1), 1-23. http://dx.doi.org/10.1093/elt/54.1.47 
Muncie, J. (2000). Using written teacher feedback in EFL composition studies. ELT Journal, 54/1.

Murray, D. (1978). Internal revision: A process of discovery. In Copper, C. and Odell, L. (eds.), Research on composing. Urbana, IL: National Council of Teachers in English.

Nation, I. and Macalister, J. (2011). Case studies in language curriculum design. Routledge, Taylor \& Francis Group.

Nunan, D. (2011). Language and culture. Routledge, Taylor \& Francis Group.

Omaggio, A. (1986). Teaching language in context: Proficiency-oriented instruction. Boston, MA: Heinle and Heinle Publishers, Inc.

Owens, R. (1970). Teaching English composition. A journal of English language teaching in South-East Asia, 119-126.

Pea, R. \& Kurland, D. (1987). Cognitive technologies for writing. Review of educational research, Vol. 14, Washington: AERA.

Pearce, L. (1998). Introducing a narrative essay: a painless way to start an academic writing program. Modern English Teacher, 7(1).

Perl, S. (1979). The composing process of unskilled college writers. Research in the teaching of English, 13(3), 17-36.

Porte, G. (1995). Writing wrongs: Coping as a strategy for underachieving EFL writers. ELT Journal, 49/2. http://dx.doi.org/10.1093/elt/49.2.144

Purves, A. (1988). Writing across languages and cultures: Issues in contrastive rhetoric. Sage Publications.

Ramanathan, V. (2003). Written textual production and consumption in vernacular and English-medium settings in India. Journal of Second Language Writing, 12, 125-150. http://dx.doi.org/10.1016/S1060-3743(02)00108-X

Reichelt, M. (2001). A critical review of foreign language writing research on pedagogical practices. Modern Language Journal, 85, 578-598. http://dx.doi.org/10.1111/0026-7902.00127

Reynolds, D. (2010). Assessing Writing, Assessing Learning. Ann Arbor., MI: University of Michigan Press.

Riessman, C. (1993). Narrative analysis. Qualitative research methods (Vol. 30). London: Sage Publications.

Rnutson, E. (2006). Thinking in English, writing in French. The French Review, 80(1), 88-109.

Robinson, P. \& Ellis, N. (2011). Handbook of cognitive linguistics and second language acquisition. Routledge, Taylor \& Francis Group.

Roca de Larios, J., R. \& Murphy, L. (2006). Generating text in native and foreign language writing: a temporal analysis of problem solving formulation process. The Modern Language Journal, (90), 100-114. http://dx.doi.org/10.1111/j.1540-4781.2006.00387.x

Rohman, G. (1965). Pre-writing: The stage of discovery in the writing process. College Composition and Communication, 16, 106-112. http://dx.doi.org/10.2307/354885

Rubin, A. (1983). The computer confronts language arts: Cans and should for education. In Wilkinson, A. (ed.), Classroom computers and cognitive science. New York: Academic Press.

Rumelhart, D. \& Ortony, A. (1975). the representation of knowledge in memory. In Anderson, R., Spiro, R. and Montague, W. (eds.), Schooling and the acquisition of knowledge. Hillsdale, NJ: Lawrence Erlbaum Associates.

Schoonen, R. \& Gelderen, A. (2003). First language and second language writing: The role of linguistic knowledge, speed of processing, and metacognitive knowledge. Language Learning, 53(1), 165-202. http://dx.doi.org/10.1111/1467-9922.00213

Scollon, S. (1999). Not to waste words or students: Confusion and Socratic discourse in the tertiary classroom. In E. Hinkel (Ed.), Culture in Second Language Teaching and Learning (pp. 13-27). New York: Cambridge University Press.

Scribner, S. \& Cole, M. (1981). The Psychology of Literacy. Cambridge, MA: Harvard University Press.

Sebba, M., Mahootian, S. \& Jonsson, C. (2011). Language mixing and code switching in writing. Routledge, Taylor \& Francis Group.

Segalowitz, N. (2011). Cognitive bases of second language fluency. Routledge, Taylor \& Francis Group.

Seliger, H. (1979). On the nature and function of language rules in language teaching. TESOL Quarterly, Vol. 13, 
359-369. http://dx.doi.org/10.2307/3585883

Silva, T. \& Leki, I. (2004). Family Matters: The influence of Applied linguistics and composition studies on second language writing studies - past, present and future. The Modern Language Journal, 88(4), 1-13. http://dx.doi.org/10.1111/j.0026-7902.2004.00215.x

Simon, H. (1970). The sciences of the artificial. Cambridge, MA: The MIT Press.

Soter, A. (1988). The second language learner and cultural transfer in narration. In A. Purves (ed.), Writing across languages and cultures: Issues in contrastive rhetoric. Sage Publications.

Spada, N. \& Lightbown, P. (2008). Form-focused instruction: Isolated or integrated. TESOL Quarterly, 42(2), 181-207.

Taylor, B. (1976). Teaching composition to low-level ESL students. TESOL Quarterly, 10(3), 309-319. http://dx.doi.org/10.2307/3585708

Terry, R. (1989). Teaching and evaluating writing as a communicative skill. Foreign Language Annals, 22(1), 43-54. http://dx.doi.org/10.1111/j.1944-9720.1989.tb03142.x

Tyler, A. (2011). Applying cognitive linguistics. Routledge, Taylor \& Francis Group.

Vahapassi, A. (1982). On the specification of the domain of school writing. In Purves, A. and Takala, S.(eds.), An international perspective on the evaluation of written composition. Oxford: Pergamon.

Vahapassi, A. (1988). The problem of selection of writing tasks in cross-cultural study In Purves, A. (ed.), Wiring across languages and cultures: Issues in contrastive rhetoric. Sage Publications.

Van Weijen, D., Van den Bergh, H. Rijlaarsdam \& Sanders, T. (2008). Differences in process and process product relations in $\mathrm{L}_{2}$ writing ITL. International Journal of Applied Linguistics, 156, 203-226. http://dx.doi.org/10.2143/ITL.156.0.2034433

Vygotsky, L. (1962). Thought and Language. New York: John Wiley and Sons, Inc. http://dx.doi.org/10.1037/11193-000

Walker, J. (2011). Variation in linguistic systems. Routledge, Taylor \& Francis Group.

Wang, J. (2005). Cognitive strategies adopted by Chinese students when writing in English. Asian Journal of English Language Teaching, 15, 25-42.

Wang, L. (2003). Switching to first language among writers with differing second-language proficiency. Journal of Second Language Writing, 12: 347-375. http://dx.doi.org/10.1016/j.jslw.2003.08.003

Wang, W. \& Wen, Q. (2002). $\mathrm{L}_{1}$ use in the $\mathrm{L}_{2}$ composing process: An Explorating study of 16 Chinese EFL writers. Journal of Second language Writing, 11, 225-246. http://dx.doi.org/10.1016/S1060-3743(02)00084-X

Weijen, D., Bergh, H. \& Rijlaarsdam, G. \& Sanders, T. (2009). $\mathrm{L}_{1}$ use during $\mathrm{L}_{2}$ writing: an empirical study of a complex phenomenon. Journal of Second Language Writing, 18, 235-250. http://dx.doi.org/10.1016/j.jslw.2009.06.003

Zimmerman, R. (2000). $\mathrm{L}_{2}$ writing: Sub-process, a model of formulating, and empirical findings. Learning and Instruction, 10, 73-99. http://dx.doi.org/10.1016/S0959-4752(99)00019-5 


\section{APPENDIX (1)}

\section{PART ONE: BACKGROUND INFORMATION}

1. Name:

2. Country:

3. Sex: Female:

Male:

4. Birth Date:

5. How long did you study English in your country?

6. How long have you been in the U.S.A.?

7. Had you ever been in an English speaking environment before coming to the United States?

8. If your answer to Question (7) is 'YES' - please, state how long? And where

\section{PART TWO:}

9. What did your previous English classes give most attention to? Please number in order of importance, \#1 being the most important, \#5 the least important.

$\begin{array}{ll}\text { Listening } & \text { Reading } \\ \text { Vocabulary } & \text { Grammar }\end{array}$

10. In your home country, what did your teacher of English give attention to in teaching writing? Please, number in order of importance, \#1 being the most important, \#5 being the least important.

$\begin{array}{ll}\text { Content } & \text { Organization } \\ \text { Language use } & \text { Grammar }\end{array}$
Vocabulary

11. Do you think learning to write in English is important? Please explain your answer.

12. Do you think learning English grammar affects your writing in English? Please, explain your answer.

13. Did you learn to write English compositions in the form of stories?

Yes No

14. If your answer to Question (13) is 'YES', where did you learn it? In the U.S.A. Back Home

15. Did you learn to write English composition to convince someone else of your opinion? Yes No

16. If your answer to Question (15) is 'YES', where did you learn it? In the U.S.A. Back Home

\section{APPENDIX (2)}

\section{WRITING TASK ONE: NARRATIVE ESSAY}

Think back to when you arrived in the United States for the first time. Write a story about a problem or experience you had. Be sure to clearly describe this problem where it happened, who was involved, how you felt at that time, and how you reacted. 
APPENDIX (3)

Table 1. Distribution of the subjects

\begin{tabular}{|c|c|c|c|c|c|}
\hline SUBJECTS & COUNTRY & AGE & $\begin{array}{c}\text { YEARS OF } \\
\text { LANGUAGE }\end{array}$ & $\begin{array}{c}\text { YEARS OF } \\
\text { EXPOSURE } \\
\text { TO ENGLISH IN } \\
\text { U.S./ENGLAND }\end{array}$ & SPECIALIZATION \\
\hline \multicolumn{6}{|l|}{ ARABIC } \\
\hline 1 & Syria & 30 & 10 Years & 5 Years & Linguistics \\
\hline 2 & Saudi Arabia & 25 & 6 Years & 5 Years & Physical Education \\
\hline 3 & Saudi Arabia & 34 & 4 Years & 4 Years & Instruction/learning \\
\hline 4 & Egypt & 44 & 10 Years & 3 Years & Instruction/Learning \\
\hline 5 & Kuwait & 33 & 12 Years & 4 Years & Public Administration \\
\hline \multicolumn{6}{|l|}{ SPANISH } \\
\hline 1 & Honduras & 27 & 1 Year & 5.5 Years & Sociolinguistics \\
\hline 2 & El Salvador & $2 ?$ & 2 Years & 1 Year & Computer Science \\
\hline 3 & Paraguay & 39 & 2 Years & 2 Years & $\begin{array}{l}\text { Economic } \\
\text { Development }\end{array}$ \\
\hline 4 & Chile & 38 & 25 Years & 6 Years & Spanish Linguistics \\
\hline 5 & Honduras & 37 & 2 Months & 2 Years & History \\
\hline
\end{tabular}

Table 2. Arabic and Spanish Subjects' performance in the narrative essay

\begin{tabular}{|l|l|l|l|l|l|l|l|l|l|l|}
\hline & \multicolumn{1}{|l|}{ Arabic Subjects } & \multicolumn{3}{l|}{ Spanish Subjects } \\
\hline Tasks & $\mathbf{2}$ & $\mathbf{3}$ & $\mathbf{4}$ & $\mathbf{5}$ & Total & $\mathbf{1}$ & $\mathbf{2}$ & $\mathbf{3}$ & $\mathbf{5}$ & Total \\
\hline Narrative & & & & & & & & & & \\
\# of words & 524 & 473 & 300 & 534 & 1831 & 773 & 398 & 428 & 317 & 1916 \\
\# of errors & 18 & 3 & 9 & 14 & 44 & 18 & 16 & 12 & 22 & 68 \\
Ratio & $29: 1$ & $158: 1$ & $33: 1$ & $38: 1$ & $41: 1$ & $43: 1$ & $25: 1$ & $36: 1$ & $14: 1$ & $28: 1$ \\
\hline
\end{tabular}

Table 3. Measures of Central Tendency of Arabic and Spanish Speakers' errors in the Narrative Essay

\begin{tabular}{|l|c|c|}
\hline & Arabic Speakers & Spanish Speakers \\
\hline Mean & 8.8 & 13.6 \\
\hline Median & 9.0 & 16.0 \\
\hline Range & 18.0 & 22.0 \\
\hline Maximum & 18.0 & 22.0 \\
\hline Minimum & 0.0 & 0.0 \\
\hline
\end{tabular}


Table 4. Types and frequencies of errors made by the subjects in the narrative essay

\begin{tabular}{|l|c|c|c|c|c|c|c|c|c|c|c|c|c|}
\hline & \multicolumn{7}{|c|}{ Arabic } \\
\hline Subjects & 2 & 3 & 4 & 5 & Total & $\%$ & 1 & 2 & 3 & 5 & Total & $\%$ \\
\hline \# of errors & 18 & 3 & 9 & 14 & 44 & & 18 & 16 & 12 & 22 & 68 & \\
\hline Types & \multicolumn{7}{|c|}{} \\
\hline Preposition & 4 & & & 2 & 6 & $\mathbf{1 3 . 6}$ & 1 & 3 & 2 & 2 & 8 & 11.8 \\
\hline Sub-verb Agreement & 3 & 1 & & 1 & 5 & 11.4 & 2 & & & 1 & 3 & 4.4 \\
\hline Verb' to do' & 1 & & & & 1 & 2.3 & & & & 2 & 2 & 2.9 \\
\hline Copula & 2 & & & & 2 & 4.5 & & & & & 8 & 11.8 \\
\hline Article & 2 & & & & 2 & 4.5 & & & & 1 & 3 & 4.4 \\
\hline Tenses & 2 & & 6 & 10 & 18 & $\mathbf{4 0 . 9}$ & 4 & 1 & & 8 & 10 & $\mathbf{1 4 . 7}$ \\
\hline Pronouns & 2 & & & 1 & 3 & 6.8 & & 2 & & & & \\
\hline Noun morphology & 1 & & & & 1 & 2.3 & & 1 & & & & \\
\hline So...that vs. too....to & & 1 & & & 1 & 2.3 & & & & & & \\
\hline Missing D.O. & 1 & 1 & & & 2 & 4.5 & & & & 1 & 1 & 1.5 \\
\hline Many/Much & & & 1 & & 1 & 2.3 & & & & & & \\
\hline Inf. Vs. Gerund & & & 1 & & 1 & 2.3 & & & & & & \\
\hline Plural 's' & & & 1 & & 1 & 2.3 & & & & & & \\
\hline Verb Morphology & & & & & & 7 & 7 & & 4 & 23 & $\mathbf{3 3 . 8}$ \\
\hline Adverbs & & & & & & & 1 & & & 1 & 2 & 2.9 \\
\hline Adjectives & & & & & & & 1 & & 2 & 3 & 4.4 \\
\hline Ind. Questions & & & & & & & & 1 & 1 & & & 2 & 2.9 \\
\hline Word Order & & & & & & & & & & & & & \\
\hline Comparative Form & & & & & & & & & & & & & \\
\hline
\end{tabular}

